\title{
Corrective Feedback Preferences in Learning English as a Foreign Language: Providing A Validated and New Scale
}

\author{
Mohammad Rahimi ${ }^{1}$, Shahram Afraz ${ }^{2 *}$, Amin Karimnia ${ }^{2}$ \\ 1. Islamic Azad University, Qeshm branch, Qeshm, Iran \\ 2. Associate Professor, Islamic Azad University, Qeshm branch, Qeshm, Iran \\ 3. Islamic Azad University, Fasa branch, Fasa, Iran \\ * Corresponding author's Email: shahram.afraz1352@gmail.com
}

\begin{abstract}
The current study was an attempt to explore the underlying factor structures of the new TPCF questionnaire designed to determine EFL teachers' perceptions of the effectiveness of corrective feedbacks (CFs). To this end, both male and female EFL teachers from private language institutes were conveniently selected to participate in the study. To come up with a suitable sample for construct validation (factor analysis), care was taken to select at least 125 participants (5 participants per item included in the final version of TPCF). Two research instruments were utilized in the current study including an interview and a newly designed questionnaire by the researcher. The findings revealed that underlying factor structures of the new TPCF included type of error \& type of CF, time of feedback \& teachers' strategy, proficiency level \& preplanning, perceived by learners, negative impression \& gender difference, dominance, correction \& CF enhancement. In addition, a new TPCF questionnaire was designed for EFL teachers' perceptions of the effectiveness of corrective feedbacks. Eventually, the implications of the study are presented.
\end{abstract}

Keywords: EFL Teachers' Perceptions of CFs (TPCF), Corrective Feedback, English Learning

\section{Introduction}

For decades now, questions about the effect of corrective feedback on second / foreign language acquisition (SLA) have been hotly debated, leading to a great deal of theoretical and empirical research (Kartchava, 2016). Although the facilitative role of corrective feedback in SLA has received some empirical reinforcement, the claims regarding its role in SLA have yet to be fully or decisively substantiated. During the last two decades, the current theoretical and empirical studies on CF's role in SLA have reached a high level (Shaqaqi \& Soleimani, 2019). However, there remain controversial issues in both theoretical and empirical studies. Theoretically, without a leading theory, a new theory always criticizes or refutes the previous theories. Currently, theories in SLA field are numerous, which is due to its interdisciplinary nature (Zarei \& Rahnama, 2013). Researchers with different academic background and different pedagogical beliefs try to give account of SLA process from different perspectives. Thus, various theories are coming into play. It may hinder the development of the discipline if the confused situation continues. Empirically, experiment results are not consistent with each other, even opposite from each other. On one hand, researchers use different experiment methods and different criteria to 
evaluate the results, which will lead to different conclusions. On the other hand, there are various variables in this kind of research, such as learners' individual difference, etc. Some experiments are conducted in labs, where some variables are difficult to control and cannot be taken into consideration. One possible explanation for such contradictory results in the literature can be either the inadequate use of research instruments or use of inadequate instruments in research on corrective feedbacks. Therefore, given the dearth of locally designed context-sensitive questionnaires for measuring teachers' perceptions of CFs in Iran, the development, construction and validation of research instruments which are specifically relevant to particular research objectives and context of use seem to be a necessity in the field. This study is an attempt to focus on "corrective feedback" from many different points of view in both EFL and ESL contexts. It also tries to ponder over the principles which are at the heart of the construct; the most significant part of this study is to try to design and validate a new context-specific scale for measuring the EFL teachers' perceptions of CFs (TPCF) whereby one can determine which types of corrective feedbacks are perceived to be more effective. Designing and validating such a scale can be very beneficial for future research and practical intentions.

As confirmed by experts in the field, the quest for applying certain types of CFs is not actually a global trend. Therefore, developing and validating a new TPCF scale specifically relevant to and applicable in EFL contexts seems quite necessary. The results of the current study, thus, can pave the ground for enhancing our understanding of the concept of CF for teaching and learning purposes since teachers' choice of CFs needs to be examined more profoundly from different aspects. Validation of such questionnaire can also be helpful for better instructional decision makings in language learning and teaching as it is a context-specific scale. To achieve the objective of the study the following research questions were proposed.

R.Q.1. what are the underlying factor structures of the new TPCF questionnaire designed to determine EFL teachers' perceptions of the effectiveness of corrective feedbacks?

R.Q.2. what are Iranian EFL teachers' perceptions of the effectiveness of different types of corrective feedbacks?

R.Q.3. To what extent male and female teachers' perceptions of the effectiveness of different types of corrective feedbacks are noticeably different?

\section{Literature Review}

For decades, corrective feedback has been hotly debated and has been a great deal of the theoretical and empirical research. Corrective feedback is essential in language education. Many studies have been done on corrective feedback which have been mostly oriented to teachers' preferences rather than to learners' preferences (Rasaee \& Khorshidi, 2013). Research on corrective feedback (CF) has also been driven by a very practical issue - what should be done when learners make errors in inside the classrooms? Ever since Hendrickson (1978) raised the question of 'how errors should be corrected?' many researchers have devoted their effort into this direction. Some started their enquiry from identifying different types of CF strategies that teachers use in L2 classrooms and others have tried to find solutions to the challenges such as the timing of CF, the efficacy of CF and the choice of errors to correct (Ellis, 2009). 
The choices of errors to correct is perhaps the most widely cited challenge or dilemma declared by practicing teachers. Although, through experience, teachers gradually form what Kumaravadivelue (2012) called "sense of plausibility" telling them what to do in response to immediate contextual demands, the issue of which errors to correct has remained a controversial phenomenon among practitioners in the field.

Rassaei and Khorshidi (2013) investigated the effect of EFL learners' gender on their preferences for corrective feedback through a questionnaire which was administered to 100 participants (50 males and 50 females) studying ELT at B.A. at Shiraz Azad University. They finally concluded that there were no statistically significant differences between males and females regarding their preferences for corrective feedback except for their choice of necessity of error correction and the no corrective feedback option. It was also realized that clarification request and repetition were the most frequent feedback while explicit feedback was the least frequent feedback among males and females.

Budiani (2011) also investigated male and female American native teachers' use of corrective feedback strategies in the classroom. The finding revealed that both male and female native-American teachers used repetition with change in their response to the learners. This strategy helps learners to understand their errors and also, to give correction on their errors. Both of them preferred direct strategies more than indirect ones. In addition, they used combination of strategy in correcting errors.

Ostovar-Namaghi and Shakiba (2015) conducted a qualitative data-driven study which aims at theorizing practice, rather than enlighten practice through theory-driven research. They made use of twenty EFL teachers' perspectives concerning corrective feedback and rigorous coding schemes of grounded theory in their study. The results led to the specification of context-sensitive corrective feedback techniques such as direct feedback; indirect feedback such as recast, providing an alternative, asking other learners, pausing before the error, presenting the rule, using the correct form and showing surprise; feedback through other language skills including writing and listening; and no correction on cognitive, affective and information processing grounds. They suggested a set of specifications on when, where, and why to use these techniques and claimed that their findings help practitioners get in-sights and improve their providing feedback and help researchers modify their hypotheses before testing them through the quantitative research that aims at generalization.

Vilček (2014) studied to find out which techniques of oral corrective feedback are the most commonly used in English language classroom and how learners perceive oral corrective feedback in general. He intended to investigate what factors may influence learners' attitude towards feedback. The findings illustrate that the choice of corrective feedback depends on the type of the lesson and that school teachers tend to use recasts as a corrective technique. It was also realized that recasts cannot prevent learners from making further errors. Learners, in this study, preferred being given the chance to self-correct their errors and that they didn't like when they are interrupted during their turns.

Vasquez and Harvey (2010) investigated the thoughts and beliefs about corrective feedback of graduate students in applied linguistics. The study was conducted at a public university in the USA among the students of graduate course of English language. The participants of the study were nine students between 
25 and 60 years of age. The data were collected by using different methods: research report, post-course questionnaire, a reflective essay, and a reflective journal. This study examined how students ${ }^{\text {ee }}$ thoughts and attitudes shift and change over the semester. At the beginning of the semester, the students had very little knowledge about corrective feedback and were afraid of its possibly threatening nature and its effect on students ${ }^{\text {ee }}$ self-esteem and motivation. However, on the post-interviews and reports, the attitudes of all participants changed significantly. They decided to focus on other aspects of corrective feedback, for example its interaction with uptake, the nature and the type of error, the role and function of feedback, and frequency. They were also very surprised that the method they most frequently used were recasts because they were aware that recasts lead to no uptake, and that they are not the best technique for improving their students ${ }^{e c}$ knowledge. They gained a more sophisticated view of corrective feedback compared to the attitude they had at the beginning of the semester. They became aware that corrective feedback is nothing to be afraid of and that there is nothing negative about it, but that there are a lot of aspects of feedback to take into consideration and to be careful about.

In more recent studies, Akbar (2017) investigated the effect of asynchronous and synchronous computermediated communication (CMC) corrective feedback on learner uptake. An introductory task, and a video-prompted discussion task via an online chat program were used as synchronous tasks. A 3-day travel plan via email was taken as the asynchronous task. According to the findings, asynchronous and synchronous computer-mediated communication (CMC) corrective feedback had a significant effect on learner uptake. Sarandi and Çelik (2018) investigated the effects of explicit recasts and output-only prompts on learning English third person '-s'. To this aim, a quasi-experimental design was used. Data analysis showed the significant and positive effect of explicit recast on the participants' learning English third person '-s'. Zhai and Gao (2018) investigated the effect of corrective feedback on EFL speaking task complexity. According to the findings, clarification quest, metalinguistic feedback and recast proved to be more effective in improving EFL speaking task complexity than the other types of corrective feedback. Shaqaqi and Soleimani (2019) examined the effects of two types of written corrective feedback (WCF) (asynchronous computer-mediated and conventional paper-and-pen metalinguistic feedback) on the use of verb tense among intermediate L2 learners. The ANOVA results revealed that although both types of WCF contributed to significant enhancement of the learners' verb tense accuracy, the effect of computer-mediated asynchronous feedback was more dominant.

\section{Method}

This validation study can be considered as a mixed methods study because it benefited from both qualitative (using interview) and quantitative (using questionnaire) procedures.

\section{Participants}

215 male and female EFL teachers (busy teaching in private language institutes) were conveniently selected to participate in the study. To come up with a suitable sample for construct validation (factor analysis), care was taken to select at least 125 participants (5 participants per item included in the final version of TPCF). The participants were aged from 27 to 38 years old. Consulting with the valid references on research in education (e.g., (Creswell, 2015), this sample size was suitable for the purpose 
of the present study.

\section{Instruments}

The instruments which were used in this research included the newly designed questionnaire by the researcher in the field and a semi-structured interview.

The items of the questionnaire were designed based on the previous literature of the construct and the theoretical principles of it. Theoretically, this questionnaire was built on the views proposed by Corder (1967), Desouky (2016), Ellis (1994), Keh (1990), etc. on corrective feedback and its effectiveness in the process of language learning. At first a pilot version of the questionnaire was applied to ensure the relevance and clarity of items. The final version was then validated based on principal component analysis (PCA).

Moreover, a semi-structured interview was run to explore the underlying factor structures of the new TPCF questionnaire. The credibility and dependability of interview data were checked through lowinference descriptors and member checking.

\section{Procedure}

To collect the data, first the sample was selected through convenience sampling. Moreover, they were told that their participation in study is voluntarily. Furthermore, a reward was given to them for their kind cooperation. Then, 20 participants were voluntarily selected and interviewed individually. Following that, through merging interview data and consulting the relevant literature, the underlying factor structures of the new TPCF questionnaire were extracted so that the questionnaire can be developed.

Next, a total of 110 questionnaires were administered through face-to-face contact and 105 via Emails. From among this number, a total of 135 questionnaires were returned to the researcher with a response rate of $60 \%$. Out of these 215 questionnaires, 10 ones were discarded. Some questionnaires were not filled out completely; some were filled haphazardly and lacked internal consistency. Thus, all in all, 125 questionnaires proved useful for the purpose of data analysis.

\section{Results}

The current study was set to explore the underlying factor structures of the new TPCF questionnaire designed to determine EFL teachers' perceptions of the effectiveness of corrective feedbacks, to examine Iranian EFL teachers' perceptions of the effectiveness of different types of corrective feedbacks, and evaluate Iranian male and female teachers' perceptions of the effectiveness of different types of corrective feedbacks. In order to analysis the interviewees' responses first the gathered data were coded and reported. The coding procedures were conducted based on the frequency of 12 criteria. For the ease of the readers, all criteria with related sub-categories are presented in Table 1. 
Table 1. Corrective Feedback Criteria with Related Sub-categories

\begin{tabular}{|c|c|c|}
\hline No. & Criteria & Sub-categories \\
\hline \multirow[t]{5}{*}{1} & \multirow[t]{5}{*}{ Types of error } & Vocabulary \\
\hline & & Mistake and error \\
\hline & & Local error \\
\hline & & Global Error \\
\hline & & Basic grammar \\
\hline \multirow[t]{2}{*}{2} & \multirow[t]{2}{*}{ Types of CF } & Witten \\
\hline & & Oral \\
\hline \multirow[t]{2}{*}{3} & \multirow[t]{2}{*}{ Time of feedback } & While task \\
\hline & & After Task \\
\hline \multirow[t]{5}{*}{4} & \multirow[t]{5}{*}{ Teachers strategy } & Students \\
\hline & & Situational Context \\
\hline & & Nature of task \\
\hline & & Repetition \\
\hline & & Asking Question \\
\hline \multirow[t]{5}{*}{5} & \multirow[t]{5}{*}{ Proficiency level } & No CF \\
\hline & & Indirect (e.g. Recast) \\
\hline & & Direct \\
\hline & & Indirect $\mathrm{CF}$ \\
\hline & & Direct CF (e.g. metalinguistic CF) \\
\hline \multirow[t]{2}{*}{6} & Preplanning & Learner Level \\
\hline & & Learner Proficiency \\
\hline 7 & & Monitoring \\
\hline & & Make a change \\
\hline & Perceived by learners & Awareness \\
\hline 8 & Negative Impression & Proper Method \\
\hline & & Positive Feedback \\
\hline & & Patience \\
\hline & & Affective Filter \\
\hline 9 & Gender Difference & Male \\
\hline & & Female \\
\hline 10 & Dominance & Atmosphere \\
\hline & & Teacher (e.g. Level of learners) \\
\hline & & Peer (e.g. Embarrassment) \\
\hline 11 & Correction & Total Ignorance \\
\hline & & Total Correction \\
\hline & & Situational-based Correction \\
\hline 12 & CF Enhancement & Timing \\
\hline & & Teachers' Role \\
\hline & & Nature of $\mathrm{CF}$ \\
\hline & & Learners' Role \\
\hline
\end{tabular}

Regarding the types of the error, most EFL teachers argued that the learners lexical and vocabulary errors are among the conspicuous errors they commit. In fact, the learners might use different vocabulary sent through opposite messages or conflicting messages that the teachers would say is very important to be brought to student's attention and to be corrected. 
In addition, sometime learners make some mistakes which are aware of them but due to the stress they make mistakes and all are forgivable but some mistakes are made by poor knowledge in any skills and must be corrected ASAP. Accordingly, the errors are divided into local and global errors. Local errors they do not hinder the communication and they are not buried to convey meaning. Based on the interviewees' responses, the teachers in dealing with such errors should ignore the local errors. Moreover, attention must be paid to global errors rather than local ones and the process of error correction should occur with consistency and systematicity. Most of the teachers maintain that the frequent errors do not hinder the communication process and can be corrected at any time.

Concerning the global errors, serious spoken errors must be corrected all the time because this can cause problems for listeners understanding and hinder the communication. Actually, we can ignore the errors as far as they do not damage the communication process. In fact, errors have an impact in the meaning or the results that the student is trying to achieve. Global errors should be at the first priority of the correction because they have higher frequency at elementary levels but in the higher levels. Global errors should be always prevented because they stand in the way of the communication. Furthermore, the global errors hinder the communication and maybe they are misunderstanding and misjudgment so, the global errors should be treated first.

The second criteria of teachers' corrective feedback are types of CF, which are divided into written and oral. In written $\mathrm{CF}$, the feedback is given separately after the whole output is given and this type of feedback is given in a written form that encompasses a linguistic correction as well.

Regarding Time of Feedback, two categories are presented as while task CF and after task CF. It is upon the teacher to figure out the right time for providing the feedback given right after the error. But in the elementary levels the teachers must be more cautious so they have to use the immediate CF. That is because that the younger students may follow the same way.

Thus, teachers have to let the learners commit errors and continue their conversation. If teachers correct them immediately, they will not pay heed to it and the only negative aspect of outright correction is that the students will be demotivated and intimidated of communicating in coming days and week. In sum, the results revealed that there was no consensus among the teachers on either while task $\mathrm{CF}$ and after task $\mathrm{CF}$.

Concerning teacher's strategy, as long as the teaching strategies differ in some different teaching tasks, the corrective feedback to the learners should be different in for example: Giving a summary, role playing, question and answer exchanges. Every single task demands its unique technique of CF. Tax complexity and the nature of the task is an important element in choosing the appropriate strategy for the corrective feedback.

In terms of preplanning in $\mathrm{CF}$, teachers will arrange to consider some general corrective feedback that will correct the wrong structure students have in their minds. It always raises the awareness of what teachers do in the classrooms.

Concerning the learners' level and preference, most teachers believe what they are concerned about most is the different level of knowledge the students have. Students frequently ask teachers to correct 
their mistakes or not and how do they like to be corrected. Definitely most of them do not like explicit $\mathrm{CF}$ and they prefer to be corrected in implicit or in the recast way. Asking the students about their preferences in the error correction and analyzing their responses can enable and enhance the use of $\mathrm{CF}$ techniques in the classrooms.

In terms of the CF perceived by learners, three elements should be considered: monitoring, make a change, and awareness. In monitoring, leaners monitor their own learning process and the way they make mistakes. Teacher should ask them participate in correcting and finding out the mistake of themselves. For making a change, the learners can perceive the change from the point having error whiling representing an output to the point they can speak or write a natural Second or Foreign language.

On the effect of negative impression on $\mathrm{CF}$, most interviewees pointed out that for avoiding the negative impressions they often implement the recast as favorite CF method and also correct students at the end of the classrooms. Then, they have to be more specific and clearer about their CF comments and correcting their mistakes.

In terms of the affective filter, most respondents argued that when they want to give them a feedback to one of their students and learners maybe makes them sad or maybe that if teachers feel that specific feedback has some negative impression teachers try to make them in a way that do not make students sad. For example, sometimes teachers give a student one of their good points. They encourage him if his or her speaking is really good. First, teachers tell them your speaking is really great and better than most of the students but in this part, teachers have some problem that they have to change it and avoid negative impressions.

The gender difference is one of the important criteria of CF. Of course, the correction strategies should be a little different based on the gender we are correcting. Definitely, most teachers argued that because in EFL classes the females have more anxiety and shyness in regards to males, and it's more recognized in our country this can be due to cultural differences and society limitations for females. It also depends on their level and the student's behavior because some males and females never like to receive explicit CF.

Regarding the dominance, in some classes the students are so satisfied with the teachers in some other classes. The students are so relaxing together. Most teachers believe that the teacher dominance should be in priority. Most studies on the teacher cognition in corrective feedback reveal that teacher feedback has a greater impact than peer feedback. Teachers also believed that the teacher comments lead to more learning development than peer feedback.

In terms of self- or peer-correction, teachers argued that in the beginning years they preferred the teacher correction but now they insist on self-correction and peer correction. At the beginner levels, they correct the students but at the higher levels they use peer correction and self-correction as well.

In terms of the total ignorance, a teacher who tends to ignore all of the errors will soon come across with the fossilization of the wrong structure in the learner's learning process. On the other hand, the errors must not be ignored at all cost. Teachers believed that ignoring all errors is not really acceptable and 
trying to correct whatever errors happen during the process of learning is wrong too. In fact, ignoring all erroneous structures by the teachers deviates the language and leads the learners to the hydra island. Concerning total correction, overcorrecting or correcting every single mistake is a harmful tool that can damage the students learning and bring the loss of motivation and interest in the learning process. Teachers argue that not all the errors should be corrected because it brings lots of tiredness and frustration for the students. When teachers just correct the errors all the time. it has some bad effects or detrimental effects on the learners. For example, one of them is just a heuristic effect. Maybe the students will not be motivated enough to speak and also it might suppress feelings and they might lose their self-confidences. so, another effect might be on effective factors of the students.

In terms of situation-based correction, ignoring or correcting all of the errors, has a negative impact on the learners' appropriate acquisition of a second or foreign language. As long as a teacher tries to correct all of the errors that have taken place, the action will impose a bad learning experience on the learners' mind and will also lead to a great deal of disturbance. Some mistakes or errors should be ignored so the students do not lose their interest. Teachers must be so cautious about the time and the type of CF that they give to the students and also there should be a balance in the correction times of teachers. Some errors have to be ignored so the students don't lose their interest in the learning. If teachers give them a feedback or correct them in every single part of learning process, it makes them really confused and sometimes makes them angry. In fact, teaching needs to be tailored as much as possible to suit a classroom's needs collectively and then an individual need as much as realistically possible for it to be a pleasant and also an enriching experience.

Finally, regarding the $\mathrm{CF}$ enhancement, one of the best tools to enhance the usefulness of the $\mathrm{CF}$ is to present them at the best time. It should not be sooner or later than what students expect to hear. The old schools they are just correct at the time of speaking. They will write the errors on the board and they will correct them. But, right now we have got different ways in order to correct them. So, different ways and keeping the journal of the learner errors.

In addition, to enhance the corrective nature of the feedbacks it's upon teachers to represent their feedback to the point and make sure the feedback will eliminate the error and prevent further misunderstanding and confusion in the learning process.

So, enhancing the nature needs some form of a bond or trust between the student and a teacher. Encourage them to speak as right as they can and make it a precious goal. One of the supporting steps that the teachers can consider in correcting their students is that keeping their students abreast of the nature of the errors and let them know that errors are inseparable part of language learning and they can climb to the highest peaks by the ladder of errors. The teacher should choose different forms of corrective feedbacks wisely based on specific situations, learners and learning tasks. When teachers change their roles from authorities to facilitators, students may pay attention to the usefulness of corrective feedbacks more than before and corrective feedback will be more effective.

In sum, based on the criteria on CF discussed, the following model can be presented as the Iranian EFL corrective feedback model. 


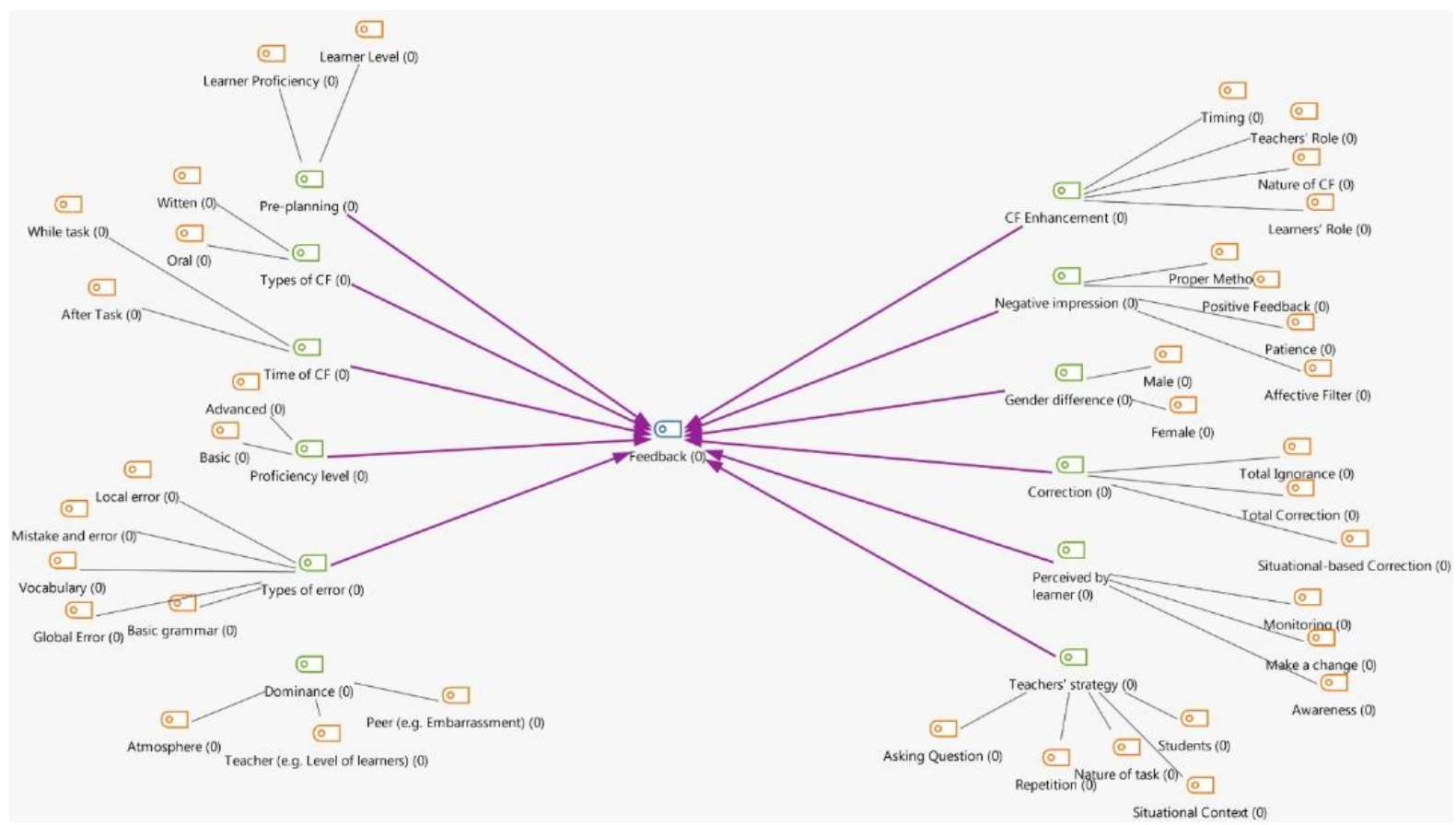

Figure 1. Iranian EFL Corrective Feedback Model

The researcher carefully reviewed and analyzed the interviews as well as literature on corrective feedback which served as basis and guide in the construction of the items in the questionnaire. These related literatures were derived from books, studies, and internet materials. Ten expert judges were consulted. They corrected and suggested more items in the initial draft of the questionnaire. These experts were all TEFL researchers who specialized in the field of ELT. They were provided with the first draft of the questionnaire where the characteristics or attributes of corrective feedback were stated and listed. The experts were asked to write their suggestions and additional statements that were not included in the list. The experts checked the items of the questionnaire which they believed were correct and worthy of inclusion in the test. Some items were refined and corrected by the experts; some were deleted because they perceived them to be inappropriate. Also, the experts provided some statements/items that were included in the second draft of the questionnaire.

The items in the initial questionnaire were expressed in just one statement. However, there was a little difficulty in finalizing the items to be included in the initial list. Some items were found to be somewhat similar with the other items and some did not implicitly characterize the distinctiveness of corrective feedback on particular categories of ELF teachers. This difficulty was resolved through integrating and incorporating the corrections and the suggested items given by the experts. The Table 2 revealed the indicators per category of corrective feedback. 
Table 2. Initial Items of Corrective Feedback Questionnaire

\begin{tabular}{|c|c|c|c|c|c|}
\hline $\begin{array}{l}\text { Initial Questionnaire } \\
\text { Items }\end{array}$ & Sources of Items & & & & $\begin{array}{l}\text { Total } \\
\text { Items }\end{array}$ \\
\hline $\begin{array}{l}\text { Categories of Corrective } \\
\text { Feedback }\end{array}$ & $\begin{array}{r}\text { Related Literatures } \\
\text { (Item, No.) }\end{array}$ & Total & Experts (Item, No.) & Total & \\
\hline $\begin{array}{r}\text { Type of Error \&Type } \\
\text { of CF }\end{array}$ & $\begin{array}{r}1,2,3,4,5,6,8,10,12,14,17 \\
18\end{array}$ & 12 & $7,9,11,13,15,16$ & 6 & 18 \\
\hline $\begin{array}{l}\text { Time of Feedback \& } \\
\text { Teachers' Strategy }\end{array}$ & $2,4,7,9,10,11,1213,17$ & 9 & $1,3,5,6,8,14,15,16$ & 8 & 17 \\
\hline $\begin{array}{r}\text { Proficiency Level \& } \\
\text { Preplanning }\end{array}$ & $\begin{array}{r}2,3,5,8,9,10,11,13 \\
16,17,19,20\end{array}$ & 12 & $1,4,6,7,12,14,15,18$ & 8 & 20 \\
\hline Perceived by Learners & $2,3,4,5,6,7,9,10,14,15,16$ & 11 & $1,8,11,12,13,17$ & 6 & 17 \\
\hline $\begin{array}{l}\text { Negative Impression } \\
\& \text { Gender Difference }\end{array}$ & $\begin{array}{r}1,2,3,4,6,7,8,9,10,11 \\
17,20\end{array}$ & 12 & $5,12,13,14,15,16,18,19$ & 8 & 20 \\
\hline $\begin{array}{r}\text { Dominance, Correction, } \\
\& \text { CF Enhancement }\end{array}$ & $2,5,7,8,11,14,17$ & 7 & $1,3,4,6,9,1012,13,15,16,18$ & 11 & 18 \\
\hline Grand Total & & 63 & & 47 & 110 \\
\hline
\end{tabular}

After the items on the different categories of the questionnaire were finalized, they were arranged and distributed accordingly. Suggestions from experts were considered and integrated in the arrangement of items in the test. A table of specification for each category of CF categories was prepared in order make the distributions of items adequate and proper.

Table 3. Specification for Each Category of CF

\begin{tabular}{|l|l|l|}
\hline Category & Item & Total \\
\hline $\begin{array}{l}\text { Type of Error \&Type } \\
\text { of CF }\end{array}$ & $1,2,3,4,5,6,7,8,9,10,11,12,13,14,15,16,17,18$ & 18 \\
\hline Time of Feedback \& Teachers' Strategy & $1,2,3,4,5,6,7,8,9,10,11,12$, & 17 \\
\hline Proficiency Level \& Preplanning & $13,14,15,16,17$ & \\
\hline Perceived by Learners & $1,2,3,4,5,6,7,8,9,10,11,12$, & 20 \\
& $13,14,15,16,17,18,19,20$ & 17 \\
\hline Negative Impression & $1,2,3,4,5,6,7,8,9,10,11,12$, & 20 \\
\hline \& Gender Difference & $13,14,15,16,17$ \\
\hline Dominance, Correction, \& CF Enhancement & $1,2,3,4,5,6,7,8,9,10,11,12$, & 18 \\
\hline Total & $13,14,15,16,17,18,19,20$ & $1,2,3,4,5,6,7,8,9,10,11,12$, \\
\end{tabular}

Six categories were initially prepared for the questionnaire. Numbers of items in different categories varied. Initially, the researcher planned to construct only fifteen items for each category and only ten items would be included in the final category, but during the item construction, the items derived from literature and the items contributed by the experts exceeded fifteen. For that matter, all items were included in the initial questionnaire. This was because all items in the initial category would go through validation and the number of items in the questionnaire would depend on the items' degree of validity. 
Table 4. Valid and Invalid Items

\begin{tabular}{|l|l|l|}
\hline Category & Valid Items & Invalid Items \\
\hline Type of Error \&Type of CF & 15 & 3 \\
\hline Time of Feedback \& Teachers' Strategy & 15 & 2 \\
\hline Proficiency Level \& Preplanning & 18 & 2 \\
\hline Perceived by Learners & 17 & 0 \\
\hline Negative Impression \& Gender Difference & 15 & 5 \\
\hline Dominance, Correction, \& CF Enhancement & 18 & 0 \\
\hline Total & 98 & 12 \\
\hline
\end{tabular}

In terms of content, the experts' overall rating was 3.10 which is very satisfactory. This meant that the questionnaire showed appropriateness and comprehensiveness in terms of content. In terms of score ability, the experts rated the questionnaire 3.30 or very satisfactory, which signified that the questionnaire manifested ease in checking and recording of the scores. In terms of economy, it was evaluated 3.20 which is very satisfactory. This means that the questionnaire brought about practicality in terms of instructions, scoring and interpreting the participants' responses. In terms of the questionnaire's administrability, it was rated 3.30 or very satisfactory, this denoted that the questionnaire's specification was comprehensive and resulted into ease in administration. In terms of usability, the questionnaire was rated 3.20 or very satisfactory. This implied that it was capable of identifying the participant's dominant type of corrective feedback. Finally, the questionnaire was perceived as an additional instrument for corrective feedback evaluation among Iranian ELF teachers.

Table 5. Specification of the Final Questionnaire

\begin{tabular}{|c|c|c|}
\hline Criteria & Mean & Verbal Description \\
\hline \multicolumn{3}{|l|}{ A. Content } \\
\hline 1. Sufficiency of the categories covered by the questionnaire & 3.2 & Very Satisfactory \\
\hline 2. Suitability of the items representing each category. & 3.0 & Very Satisfactory \\
\hline 3. Accuracy of the items as indicated in the table of specification. & 3.40 & Very Satisfactory \\
\hline 4. Applicability of the items to target participants. & 3.0 & Very Satisfactory \\
\hline 5. Comprehensiveness of instructions and directions. & 3.60 & Excellent \\
\hline 6. Simplicity of the constructions of items. & 3.0 & Very Satisfactory \\
\hline 7. Distributions of items. & 3.80 & Very Satisfactory \\
\hline 8. Comprehensiveness of the items. & 3.80 & Very Satisfactory \\
\hline \multicolumn{3}{|l|}{ B. Score ability } \\
\hline 1. Ease in scoring & 3.40 & Very Satisfactory \\
\hline 2. Ease in checking and recording process. & 3.20 & Very Satisfactory \\
\hline \multicolumn{3}{|l|}{ C. Economy } \\
\hline 1. Economy in scoring and interpreting the questionnaire. & 3.20 & Very Satisfactory \\
\hline 2. Economy in reading instructions. & 3.20 & Very Satisfactory \\
\hline \multicolumn{3}{|l|}{ D. Administrability } \\
\hline 1. Ease in administering the questionnaire. & 4.20 & Very Satisfactory \\
\hline 2. Comprehensiveness of the questionnaires' guidelines. & 4.40 & Very Satisfactory \\
\hline \multicolumn{3}{|l|}{ E. Usability } \\
\hline 1. Representation of the participants' dominant type of corrective feedback. & 4.40 & Very Satisfactory \\
\hline 2. Additional instrument for feedback evaluation. & 4.0 & Very Satisfactory \\
\hline
\end{tabular}


The reliability index of the developed Iranian ELF teachers' corrective feedback was obtained through the coefficient alpha. In the initial questionnaire, it had a reliability index of 0.81 signifying a very high degree of reliability. In the final questionnaire, its reliability index was 0.82 , which only proved and showed that the questionnaire had a very high reliability or consistency within its categories.

The first research question investigated the underlying factor structures of the new TPCF questionnaire designed to determine EFL teachers' perceptions of the effectiveness of corrective feedbacks. To this end, as mentioned earlier, the analysis of data revealed that underlying factor structures of the new TPCF included type of error \& type of $C F$, time of feedback \& teachers' strategy, proficiency level \& preplanning, perceived by learners, negative Impression \& gender Difference, dominance, correction, \& CF enhancement.

To answer the second research question which explored Iranian EFL teachers' perceptions of the effectiveness of different types of corrective feedbacks all teacher participants completed the newlydesigned TPCF questionnaire. The results are shown in Table 6.

Table 6. Iranian EFL Teachers' Perceptions of the Effectiveness of Different Types of CF

\begin{tabular}{|l|l|l|}
\hline Items & Mean & SD \\
\hline Type of Error \& Type of CF & 3.58 & 2.19 \\
\hline Time of Feedback \& Teachers' Strategy & 3.04 & 2.59 \\
\hline Proficiency Level \& Preplanning & 3.99 & 2.52 \\
\hline Perceived by Learners & 3.69 & 2.46 \\
\hline Negative Impression \& Gender Difference & 3.87 & 2.23 \\
\hline Dominance, Correction, \& CF Enhancement & 3.61 & 2.78 \\
\hline
\end{tabular}

According to Table 6, Iranian EFL teachers favor various categories of CF. However, they showed willingness toward some of the categories. That is to say, the participants had a positive view on Proficiency Level \& Preplanning ( $\mathrm{M}=3.99, \mathrm{SD}=2.52)$, Negative Impression \& Gender Difference $(\mathrm{M}=3.87, \mathrm{SD}=2.23)$, Perceived by Learners $(\mathrm{M}=3.69, \mathrm{SD}=2.46)$, Dominance, Correction, \& CF Enhancement $(\mathrm{M}=3.61, \mathrm{SD}=2.78)$, Type of Error \& Type of $C F(\mathrm{M}=3.58, \mathrm{SD}=2.19)$, and Time of Feedback \& Teachers' Strategy $(\mathrm{M}=3.04, \mathrm{SD}=2.59)$, respectively.

The third research question investigated male and female teachers' perceptions of the effectiveness of different types of corrective feedbacks were noticeably different. To this end, the results obtained from two groups were compared via independent sample t-test.

Table 7. Independent Samples t-test for Male and Female Participants

\begin{tabular}{|c|c|c|c|c|c|c|c|c|c|c|}
\hline \multicolumn{4}{|c|}{$\begin{array}{l}\text { Levene's Test for Equality of } \\
\text { Variances }\end{array}$} & \multicolumn{7}{|c|}{ t-test for Equality of Means } \\
\hline & & \multirow[t]{2}{*}{$\mathrm{F}$} & \multirow[t]{2}{*}{ Sig. } & \multirow[t]{2}{*}{$\mathrm{t}$} & \multirow[t]{2}{*}{ df } & \multirow[t]{2}{*}{$\begin{array}{l}\text { Sig. (2- } \\
\text { tailed) }\end{array}$} & \multirow[t]{2}{*}{$\begin{array}{l}\text { Mean } \\
\text { Difference }\end{array}$} & \multirow[t]{2}{*}{$\begin{array}{l}\text { Std. Error } \\
\text { Difference }\end{array}$} & \multicolumn{2}{|c|}{$\begin{array}{l}95 \% \text { Confidence } \\
\text { Interval of the } \\
\text { Difference }\end{array}$} \\
\hline & & & & & & & & & Lower & Upper \\
\hline \multirow[t]{2}{*}{ Pretest } & $\begin{array}{l}\text { Equal } \\
\text { variances } \\
\text { assumed }\end{array}$ & .772 & .382 & .077 & 123 & .939 & .067 & .866 & -1.649 & 1.782 \\
\hline & $\begin{array}{l}\text { Equal } \\
\text { variances not } \\
\text { assumed }\end{array}$ & & & .077 & 121 & .939 & .067 & .866 & -1.649 & 1.782 \\
\hline
\end{tabular}


As shown in Table 7, since Levene's Test is significant ( $p>0.05)$ the equal variances assumed is taken into consideration. Therefore, in t-test for equality of means, since $p<.939$ is more than significance level $\alpha=0.05$ we conclude that the mean scores for male and female Iranian EFL teachers is not significantly different. Thus, they had equal perception on the effectiveness of different types of corrective feedbacks.

\section{Discussion}

As stated earlier, the current study was set to investigate the underlying factor structures of the new TPCF questionnaire designed to determine EFL teachers' perceptions of the effectiveness of corrective feedbacks. The findings revealed that that underlying factor structures of the new TPCF consisted of the followings: type of error \& type of CF, time of feedback \& teachers' strategy, proficiency level \& preplanning, perceived by learners, negative Impression $\&$ gender Difference, dominance, correction, $\&$ CF enhancement.

Additionally, the current study explored Iranian EFL teachers' perceptions of the effectiveness of different types of corrective feedbacks. The results indicated that the participants had a positive view on Proficiency Level \& Preplanning, Negative Impression \& Gender Difference, Perceived by Learners, Dominance, Correction, \& CF Enhancement, Type of Error \& Type of CF, and Time of Feedback \& Teachers' Strategy, respectively.

Regarding methods of CF based on Lyster and Ranta (1997), clarification request, repetition, explicit feedback, elicitation, metalinguistic feedback and recast did not make a difference between male and female learners while the no $\mathrm{CF}$ option indicated difference between these two groups. So, the relationship between learners' gender and their preferences was found statistically significant only for the necessity for error correction and no CF as an option to address learners' errors. Lyster and Mori (2006) concluded that effective CF types were different in form-oriented and meaning-oriented classes. Lyster and Mori (2006) also reported that uptake occurred most frequently after recasts in EFL classrooms. That is due to the fact that in immersion classrooms, teachers expected the students to speak accurately. They also expected the students to repeat the teachers' recasts in order to practice the forms during discourse. The use of $\mathrm{CF}$ approaches as prompts, such as clarification requests or elicitations, resulted in the most frequent uptake in other ESL classes where meanings and content are focused more than the accuracy of forms.

Concerning the relationship between the situational context and teachers' CF preferences, the results of the present study were in line with Oliver and Mackey (2003) who indicated that educational context influences types of CF. Nabei and Swain (2002) also suggested that the awareness of recast as a CF is influenced by "the teaching environment, the interaction context, and the learner's cognitive orientation" (p. 43). The findings support the results reported by Zhang and Rahimi (2014) according to which various external factors influence kinds of CF. Moreover, the same results were found by Iraji, Zoghi, and NematTabrizi (2014). 
The findings of the current study are line with those in Diab (2006), Halimi (2008), and Deng (2010). Moreover, they agreed on the types of grammatical errors that should be corrected and looked at some grammar corrections more carefully than at others. That is, the correction of errors in word and verb categories was more important to them than that of other grammatical errors. The results also partially confirm those of Ferris and Roberts (2001). Their study showed that one of the most problematic grammatical elements in writing for those L2 student-writers who had limited prior exposure to English outside the language classroom belonged to word choice categories. In Rahimi's (2010) study, L2 students also showed highest preferences for receiving feedback on this error type. English verb tenses and aspects also appear to be difficult for the Iranian learners of English. Rahimi (2010) also found that verb errors can be considered difficult to be self-corrected, at least for the Iranian learners of English unlike what Ferris and Roberts (2001) claimed.

Similarly, Deng (2010) reported the students' strong desire for receiving direct feedback on grammatical errors. Moreover, the students' preferences for comprehensive feedback in this study confirm those obtained by Deng (2010), Lee (2005, as cited in Lee, 2008), Lee (2008), and Leki (1991).

The results also confirm those of Lee (2008). In his study, most of the high school students opted for the combination of direct feedback and indirect, coded feedback and expected their teachers not to locate errors indirectly (i.e., indirect prompting of error location).

These findings are consistent with those of studies that have investigated EFL/ESL students' attitude towards grammar feedback (Deng, 2010; Ferris \& Robert, 2001; Hamouda, 2011).

Finally, the present study was an attempt to find out whether there was any significant difference between male and female teachers' perceptions of the effectiveness of different types of corrective feedbacks are noticeably different. The finding showed that there was no significant difference between Iranian EFL male and female language teachers in terms of their perceptions of the effectiveness of different types of corrective feedbacks. Chen, Nassaji and Liu (2016) and Desouky (2016) reached the same results.

Analysis of teachers' responses to student errors is a crucial, yet neglected, area in the Iranian EFL context. In particular, little is known about how Iranian teachers respond to students' errors and whether discrepancies exist between teachers' CF and student perceptions and preferences. In the current study, most teachers thought favorably of teacher CF questionnaire and agreed that teachers' CF had a positive impact on students.

The findings of this study shed light on the nature of language learning in relation to teachers' CF. This study contributed to the present literature feedback by presenting a new model for Iranian EFL teachers' CF. In addition, these results could cast light on the issue of language proficiency. The results demonstrated that some factors are more dominant than other factors in EFL feedback. These results can also be useful to curriculum and syllabus designers providing them with information about the factors affecting language proficiency. In particular, the study provided them with this information that learning a language is not just a matter of learning grammar or vocabulary. Rather, it includes other factors like social, cultural and linguistic factors affecting CF. Many of these factors could be at least brought to the consciousness of the learners. 
Based on the results of this study, it is recommended that EFL teachers take CF seriously in the educational settings, taking various effective external and internal factors into account. Moreover, it can be suggested that EFL learners should try to benefit from different types of corrective feedback provided by their teachers in English classes.

Conflict of interest: The authors stated no conflict of interest in the study.

Financial sponsor: The authors acknowledged that they he not received any financial support for all stages of the study, writing and publication of the paper.

\section{References}

Akbar, F.S. (2017). Corrective feedback in written synchronous and asynchronous computer-mediated communication. Teachers College, Columbia University Working Papers in Applied Linguistics \& TESOL, 17 (2), 9-27.

Budiani, A. F. (2011). The strategies of giving corrective feedback used by male and female native American teachers in the classroom. Unpublished master's thesis, Petra Christian University, Surabay.

Chen, S., Nassaji H., \& Liu, Q. (2016). EFL learners' perceptions and preferences of written corrective feedback: A case study of University students from Mainland China. Asian-Pacific Journal of Second and Foreign Language Education, 1-5.

Corder, S. P. (1967). The significance of learners' errors. International Review of Applied Linguistics, 9 , 161-169.

Creswell, JW. (2015). A concise introduction to mixed methods research. Thousand Oaks, CA: Sage.

Deng, K. (2010). Rethinking error feedback on L2 writing. Retrieved from http://www.jaltpublications.org/proceedings/2009/.

Desouky, A. (2016). Effectiveness of using screencast feedback on EFL students' writing and perception. English Language Teaching, 9 (8), 106-121.

Diab, R. L. (2006). University students' beliefs about learning English and French in Lebanon. System, 34(1), 80-96.

Ellis, R. (1994). The studies in second language acquisition. Oxford: Oxford University Press.

Ellis, R. (2009). Corrective feedback and teacher development. L2 Journal, 1(1), 21-35.

Ferris, D. R., \& Roberts, B. (2001). Error feedback in L2 writing classes: How explicit does it need to be? Journal of Second Language Writing, 10, 161-184.

Halimi, S. S. (2008). Indonesian teachers' and students' preferences for error correction. Wacana, 10(1), 50-71.

Hamouda, A. (2011). Study of students and teachers' preferences and attitudes towards correction of classroom written errors in Saudi EFL context. English Language Teaching, 4(3),128-141.

Hendrickson, J. (1978). Error correction in foreign language teaching: Recent theory, research, and practice. The Modern Language Journal, 62, 387-398.

Iraji, S., Zoghi, M., \& Nemat-Tabrizi, A. (2014). Corrective feedback and learners' uptake across gender in an EFL context. Procedia - Social and Behavioral Sciences, 98, 680 - 687. 
Kartchava, E. (2016). Learners' beliefs about corrective feedback in the language classroom: perspectives from two International contexts. TESL CANADA JOURNAL, 33(2), 19-45.

Keh, C. L. (1990). Feedback in the writing process: A moral and methods for implementation. ELT Journal, 44(4), 294-304.

Khorshidi, E., \& Rassaei, E. (2013). The effects of learners' gender on their preferences for corrective feedback. Journal of Studies in Learning and Teaching English, 2(2), 71-83.

Kumaravadivelu, B. (2012). Language teacher education for a global society: A modular model for knowing, analyzing, recognizing, doing, and seeing. Routledge.

Lee, I. (2008). Student reactions to teacher feedback in two Hong Kong secondary classrooms. Journal of Second Language Writing, 17, 144-164.

Leki, I. (1991). The preferences of ESL students for error correction in college level writing classes. Foreign Language Annals, 24(3), 203-218.

Lyster, L., \& Ranta, L. (1997). Corrective feedback and learner uptake: Negotiation of form in communicative classrooms. Studies in Second Language Acquisition,19, 37-66.

Lyster, R., \& Mori, H. (2006). Interactional feedback and instructional counterbalance. Studies in second language acquisition, 269-300.

Nabei, T., \& Swain, M. (2002). Learner awareness of recasts in classroom interaction: A case study of an adult EFL student's second language learning. Language awareness, 11(1), 43-63.

Oliver, R., \& Mackey, A. (2003). Interactional context and feedback in child ESL classrooms. Modern Language Journal, 87(4), 102-134.

Ostovar-Namaghi, S. A., \& Shakiba, K. (2015). Theorizing EFL teachers' perspectives and rationales on providing corrective feedback. The Qualitative Report, 20(6), 727-745.

Rahimi, M. (2010). Iranian EFL students' perceptions and preferences for teachers' written feedback: Do students' ideas reflect teachers' practice? The Journal of Teaching Language Skills, 2(2), 75-98.

Sarandi, H., \& Çelik, M. (2018). The effects of explicit recasts and output-only prompts on learning L2 grammar. H. U. Journal of Education, 1-18.

Shaqaqi, M., \& Soleimani, H. (2019). Effects of asynchronous and conventional paper-and-pen metalinguistic feedback on L2 learners' use of verb tense. Journal of Modern Research in English Language Studies 5(3), 55-72.

Vásquez, C., \& Harvey, J. (2010). Raising teachers' awareness about corrective feedback through research replication. Language Teaching Research, 14(4), 421-443.

Vilček, I. (2014). Oral corrective feedback in EFL: Teachers techniques and learners' attitude. Doctoral dissertation, Josip Juraj Strossmayer University of Osijek. Faculty of Humanities and Social Sciences. Department of English Language and Literature.

Zhai, K., \& Gao, X. (2018). Effects of corrective feedback on EFL speaking task complexity in China's university classroom. Cogent Education, 5, 1-14.

Zhang, L.J., \& Rahimi, M. (2014). EFL learners' anxiety level and their beliefs about corrective feedback in oral communication classes. System, 42, 429-439. 